\title{
The Outcomes of Primary 23-gauge Vitrectomy in Retinal Detachment Patients with Grade C Proliferative Vitreoretinopathy Surgery
}

\section{Evre C Proliferatif Vitreoretinopatinin Eşlik Ettiği Retina Dekolmanı Hastalarında Primer 23-gauge Vitrektominin Sonuçları}

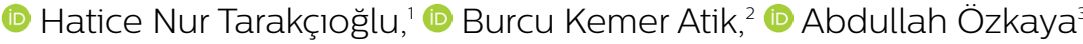

${ }^{1}$ Department of Ophthalmology, Bakırköy Sadi Konuk Training and Research

Hospital, İstanbul, Turkey

${ }^{2}$ Department of

Ophthalmology, Beyoğlu Eye Training and Research Hospital, İstanbul, Turkey

${ }^{3}$ Department of Ophthalmology, Memorial Şişli Hospital, İstanbul, Turkey

Cite this article as: Tarakçıoğlu HN, Kemer Atik B, Özkaya A. The Outcomes of Primary 23-gauge Vitrectomy in Retinal Detachment Patients with Grade C Proliferative Vitreoretinopathy Surgery. Bosphorus Med J 2019;6(3):94-98.

Received: 12.06 .2019 Accepted: 16.10 .2019

Correspondence: Dr. Abdullah Özkaya. Memorial Şişli Hastanesi, Göz Hastalıkları Anabilim Dalı, İstanbul, Turkey Phone: +905054529270

e-mail: abdozkaya@gmail.com

\section{ABSTRACT}

Objectives: To assess the outcomes of primary vitrectomy in retinal detachment (RD) patients with grade $C$ proliferative vitreoretinopathy (PVR).

Methods: In this study, retrospective, single-surgeon case series were examined. The patients who had an RD with grade C PVR and underwent 23-gauge vitrectomy, and had a minimum follow up period of 12 months were included. The primary outcome measure of this study was the anatomical success (achievement of the totally attached retina) rate after a single surgery.

Results: A total number of 42 eyes of 42 patients were included in this study. The mean age was $57.6 \pm 13.9$ years (range 27-88 years), and the mean follow-up was $17.1 \pm 4.8$ months (range 12-22 months). The anatomical success rate after a single operation was achieved in 32 of the 42 patients $(76.2 \%)$. The remaining 10 patients were operated again, and the final success rate increased to $95.2 \%$ (40 of the 42 patients).

Conclusion: The findings suggest that vitrectomy is effective in the treatment of RD with grade C PVR with satisfactory anatomical success.

Keywords: Proliferative vitreoretinopathy; retinal detachment; vitrectomy.

\section{ÖZET}

Amaç: Evre C proliferatif vitreoretinopatinin (PVR) eşlik ettiği retina dekolmanı hastalarında primer vitrektomi cerrahisinin sonuçlarını değerlendirmek.

Yöntem: Geriye dönük, tek cerrah olgu serisi. Evre C PVR'si olan ve 23-gauge vitrektomi uygulanmış ve cerrahi sonrası takip süresi en az 12 ay olan retina dekolmanı hastaları çalışmaya alındı. Çalışmanın birincil sonlanım noktası tek cerrahi sonrası anatomik başarı (retinanın tamamen yatışık olması) oranı idi.

Bulgular: Toplamda 42 hastanın 42 gözü çalışmaya alındı. Ortalama yaş 57.6ะ13.9 (27-88 arası) yıl ve ortalama takip süresi 17.1 \pm 4.8 (12-22 arası) ay idi. Kırk iki hastanın 32'sinde (\%76.2) tek cerrahi sonrası anatomik başarıya ulaşıldı. Kalan 10 hasta yeniden opere edildi ve final anatomik başarı oranı \%95.2'ye (42 hastanın 40'ı) yükseldi.

Sonuç: Evre C PVR'li retina dekolmanı hastalarında vitrektomi etkili bir tedavi yöntemidir.

Anahtar sözcükler: Proliferatif vitreoretinopati; retina dekolmanı; vitrektomi.

roliferative vitreoretinopathy (PVR) is one of the important preoperative factors which leads the surgeon to choose vitrectomy for the first line in the surgical treatment of retinal detachment (RD). ${ }^{[1,2]}$ The primary goals of surgery are finding and sealing the retinal breaks, reat- 
taching the retina and relieving the vitreoretinal traction over the retinal break and the other areas. ${ }^{[3-5]}$ As PVR usually causes significant vitreoretinal traction over the retina, vitrectomy is a valuable option in the treatment of the $R D$ cases associated with PVR. ${ }^{[3-7]}$ PVR is divided into three stages as stage A, B and C. ${ }^{[8]}$ Stage C PVR is characterized with visible preretinal and subretinal membranes or retinal foreshortening. ${ }^{[8]}$ Sophisticated vitreoretinal maneuvers, such as membrane peeling and retinotomy/retinectomy, which may be performed only during vitrectomy are usually required in cases with PVR. ${ }^{[9-11]}$ In this study, we aimed to evaluate the outcomes of vitrectomy in RD cases with stage C PVR.

\section{Methods}

The medical records of the $\mathrm{RD}$ patients with grade C PVR who were operated by a single surgeon (A.O.) between 2013 and 2016 were reviewed. A written informed consent was obtained from all patients before the treatment, and this study adhered to the tenets of the Declaration of Helsinki.

The inclusion criteria were to have an $\mathrm{RD}$ with grade $\mathrm{C}$ PVR a follow-up period of $\geq 12$ months after the first surgery and a follow-up period of $\geq 6$ months after silicone oil (SO) removal. The patients who were previously operated for RD with scleral buckling, or underwent a combination procedure with scleral buckle in the same session of the surgery or the patients with a trauma history were excluded from this study. The grading of PVR was made upon the classification of the PVR study group. ${ }^{[8]}$

The collected data included age, sex, best corrected visual acuity (BCVA), lens status, duration of RD, the status of the macula, choice of tamponade, complications, and functional and anatomical outcomes. A projection chart was used for the measurement of the BCVA, biomicroscopic evaluation of anterior and posterior segment was performed, and intraocular pressure (IOP) was measured via applanation tonometry. The post-operative examinations were performed at $1^{\text {st }}$ day, $1^{\text {st }}$ week, $1^{\text {st }}, 3^{\text {rd }}, 6^{\text {th }}$, and $12^{\text {th }}$ month. At postoperative month 12, if a patient had a postoperative BCVA $\geq 1.0$ LogMAR8, then, functional success was considered and if a patient had an attached retina, it was accepted as an anatomical success. If the retina was totally or partially detached, then, it was considered as anatomical failure. SO was permanently left in some of the patients, and these patients were accepted to have an anatomical failure.

\section{Surgical Technique}

All of the surgeries were performed by a single surgeon (A.O.). A 23-gauge transconjunctival vitrectomy with the Constellation system (Alcon Surgical, Ft. Worth, TX) and a wide-field viewing system (EIBOS, Haag Streit, Wedel, Germany) was used. If the patient was phakic and had a prominent cataract, phacoemulsification was performed before the vitrectomy. Four sclerotomies for infusion, vitreous cutter, endo-illumination, and one 25-gauge sclerotomy for Chandelier light were prepared. The first core vitrectomy was performed. Vitreous was completely removed, triamcinolone assisted vitreous base shaving was performed; vitreoretinal traction was released around all of the breaks. The subretinal membranes caused stiffness, and all of the preretinal membranes were removed. If retinal stiffness was not resolved after removal of the membranes, then, retinotomy/ retinectomy was performed. A flute needle was used to drain the existing subretinal fluid from an existing break with or without the assistance of a heavy perfluorocarbon fluid. Endolaser photocoagulation was applied to all of the breaks. The amount of additional barrier laser photocoagulation was changed according to the retinal condition. For example, if a patient did not have any peripheral retinal degeneration of membranes at the superior half of the retina, then, only 180-degree barrier laser photocoagulation was applied to the lower half of the retina, or 360-degree barrier laser photocoagulation was applied if there were diffuse retinal degenerations. Air-fluid exchange was performed, and a suitable tamponade was exchanged with air. Lastly, all of the sclerotomies were checked and sutured with $7 / 0$ polyglactin suture if leakage was present. The endotamponade choice was made according to the surgeons' preferences; however, SO was preferred in the vast majority of the cases as they were very complicated. SO was planned to be removed between month 3 and 12 postoperatively. The primary outcome measure was the anatomical success (achievement of the totally attached retina) at postoperative month 12 .

\section{Statistical Analysis}

Statistical Package for the Social Sciences software (version 21.0) was used for the analyses. The continuous variables were expressed as means \pm standard deviation. The categorical variables were expressed as number (n) and percentages (\%). Visual acuity was converted to LogMAR for statistical analysis. First, the data were analyzed concerning normality using the Kolmogorov-Smirnov test. As the distribution of 
the data was found to be normal, the visual acuity values between baseline and the other time points were assessed using repeated measures test. Categorical variables were compared using the chi-square test. A p-value $<0.05$ was considered statistically significant.

\section{Results}

Forty-two eyes of 42 patients were included in this study. The mean age was $57.6 \pm 13.9$ years (range $27-88$ years). Twenty-eight patients (66.7\%) were men and $14(33.3 \%)$ were women. The mean follow-up period was $17.1 \pm 4.6$ months (range 12-33 months). The baseline characteristics were summarized in Table 1.

\section{Anatomical Outcomes}

Single operation success was achieved in 32 of the 42 patients $(76.2 \%)$. The remaining 10 patients $(23.8 \%)$ showed recurrence, which was secondary to PVR in all of them. The mean time interval was 47.9 \pm 22.7 days (range 15-90 days) between the first surgery and recurrence of the RD. The patients who showed recurrence were operated again, and the anatomical success increased to $95.2 \%$ (40 of 42 patients) at the last follow-up visit. Two of the eyes were left with permanent SO tamponade.

\section{Visual Outcomes}

The mean baseline BCVA was 2.36 \pm 0.91 LogMAR (range 0.03.0) and increased to $1.07 \pm 0.68 \operatorname{LogMAR}$ (range 0.0-3.0) at

\section{Table 1. General characteristics of the patients}

Whole group, $\mathrm{n}=42$

$\begin{array}{lc}\text { Age } & 57.6 \pm 13.9 \text { years } \\ \text { Gender (Female/Male) } & 14 / 28 \\ \text { Lens status (Phakic/Pseudophakic/Aphakic) } & 25 / 16 / 1 \\ \text { Duration of visual decrease } & 38.5 \pm 42.2 \text { days } \\ \text { Number of retinal tears (single/multiple) } & 26 / 16 \\ \text { Presence of choroidal detachment, } \mathrm{n}(\%) & 7 \text { eyes }(16.7) \\ \text { Localization of RD (superior/inferior/total) } & 7 / 14 / 21 \\ \text { Status of the macula (attached/detached) } & 4 / 38 \\ \text { Baseline BCVA } & 2.36 \pm 0.91 \text { LogMAR } \\ \text { Tamponade (SO/C3F8) } & 35 / 7 \\ \text { Peroperative 360-degree barrier } & 15 \text { eyes (35.7) } \\ \text { photocoagulation, n (\%) } & \end{array}$

n: Number; RD: Retinal detachment; BCVA: Best-corrected visual acuity; SO: Silicone oil; C3F8: Perfluoropropane. the last follow-up visit. The mean baseline BCVA was found to be statistically increased at month 3, 6, 9, 12, and the last visit ( $\mathrm{p}<0.0001$ ) (Fig. 1). The baseline vision was increased in 34 eyes (80.9\%), did not change in six eyes (14.3\%), and decreased in two eyes (4.8\%) at the last follow-up visit. Twenty-seven eyes (64.3\%) had a BCVA $\geq 1.0$ LogMAR (functional success).

\section{Tamponades, Lens Status and Intraocular Pressure}

Tamponade C3F8 was used in seven patients (16.7\%) and SO was used in $35(83.3 \%)$ of them. The SO was removed in a mean time period of 4.1 \pm 3.1 months (range: 1-12 months).

At the baseline, 25 eyes (59.5\%) were phakic, 16 were pseudophakic (38.1\%) and one was aphakic (2.4\%). Nine of the 25 phakic eyes underwent consequent phacoemulsification at the time of the first vitrectomy. Eleven of the remaining 16 eyes showed significant cataract during the follow-up period and underwent cataract surgery. At the last follow-up visit, only six patients were still phakic.

The mean baseline and last IOP was $13.3 \pm 3.4 \mathrm{mmHg}$ (range: $5-22 \mathrm{mmHg}$ ) and $15.2 \pm 2.8 \mathrm{mmHg}$ (range: $10-21 \mathrm{mmHg}$ ), respectively. Ten eyes showed IOP elevation $(23.8 \%)$ in the early postoperative period, and six of these eyes progressed to permanent IOP elevation. All of the patients with permanent IOP elevation was controlled with topical anti-glaucomatous drugs and used a mean of $1.1 \pm 0.8$ drug (range: $1-2$ ). None of the eyes showed a phthisis bulbi or had an IOP $<6$ $\mathrm{mmHg}$.

\section{Complications}

Peroperative complications were limited with iatrogenic retinal tear, which were present in five eyes (14.3\%). Early postoperative complications were hypotony in one eye

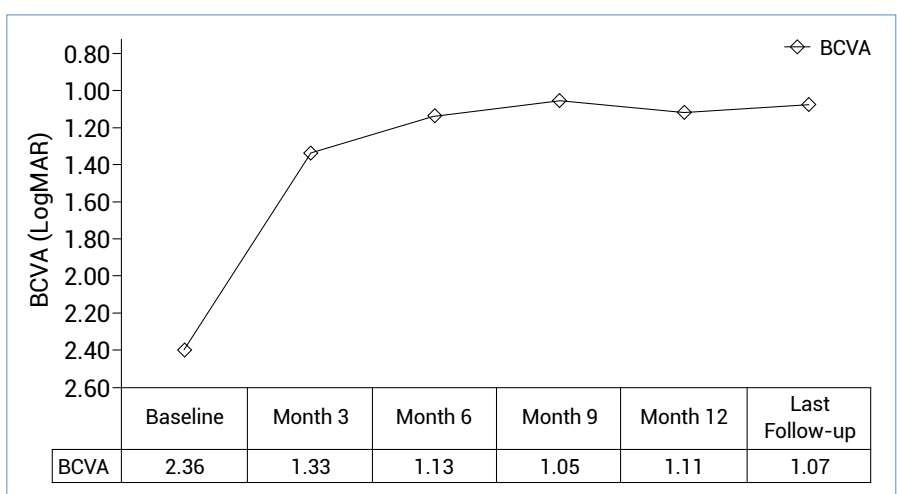

Figure 1. Best-corrected visual acuity levels of the patients at different time points. 
(2.4\%), SO migration to the anterior chamber in one eye $(2.4 \%)$, transient vitreous hemorrhage in one eye $(2.4 \%)$ and hyphema in three eyes (7.2\%).

\section{Discussion}

We evaluated the outcomes of 23-gauge vitrectomy in rhegmatogenous RD (RRD) patients who had a significant PVR in this study. Anatomic success rate was $76.2 \%$ with a single operation and the final anatomical success rate was 95.2\%. The mean baseline visual acuity significantly increased from 2.36 LogMAR to 1.07 LogMAR after a mean follow-up period of 17.1 months. The mean baseline visual acuity increased in $80.9 \%$ of the eyes. In addition, nearly three third of the eyes $(64.3 \%)$ reached a final visual acuity $\geq 1.0$ LogMAR.

In the previous series, the anatomical success rate of 20-gauge vitrectomy in RRD patients with PVR was reported between $51 \%$ and $80 \% .{ }^{[1,2,5,6]}$ In the study by IwahashiShime et al. ${ }^{[1]}$ the anatomical and functional outcomes of 25-gauge vitrectomy in 27 RRD patients with PVR were evaluated. The mean follow-up period of the study was 32.5 months, which was quite longer than our study. They reported that single surgery anatomical success rate was $77.8 \%$ and the final anatomical success rate was $92.6 \%$, and both of which were very similar to our findings in this study. Only one eye out of 27 eyes showed postoperative hypotony in their study and this eye was left with permanent SO endotamponade. They reported than a 20-gauge hybrid vitrectomy was required in nearly half of the eyes (40.7\%), especially for removing subretinal membranes. As we performed surgeries with a 23-gauge system and as the instruments were stiff enough to go under the retina, we did not require hybrid vitrectomy in any of our patients. Storey et al. ${ }^{[2]}$ compared the outcomes of pars plana vitrectomy combined with scleral buckle and pars plana vitrectomy alone in RRD patients at high risk for PVR. Sixty-five patients out of 678 were identified as high risk for PVR. The patients were accepted to have a high-risk PVR, if they showed RRD in $\geq 2$ quadrants, had retinal tears $>1$ clock hour, preoperative PVR, or vitreous hemorrhage. The patients divided into two groups, and 36 patients were included in the vitrectomy + scleral buckle group, and 29 were included in the vitrectomy alone group. All vitreoretinal surgeries were performed with a 23-gauge system. Different tamponades were used as required. The overall single operation anatomical success was $63.1 \%$. Anatomical success rate was better in the vitrectomy + scleral buckle group (75.0\%) than the vitrectomy alone group (48.3\%). Subset analysis was also performed in this study and combination surgery was more successful in patients who were $<65$ years-old whereas no significant difference was found between the two surgery groups in patients who were $>65$ years-old. The surgical success rate of the vitrectomy alone arm was $48.3 \%$ and was lower than our study, as well as the previous studies. Probably, the reason for this low success rate was the higher risk of PVR development in the chosen high-risk group.

The main limitation of this study was its retrospective design. However, the included number of patients was quite high for a single surgeon case series and the surgeon worked in a reference center with a high number of operations (5560 vitreoretinal surgeries a week). Also, these kinds of studies are very important in the self-determination of the surgeons. As the single surgery, the anatomical outcome of the study is consistent with the existing literature; the surgeon may assume that his surgical techniques were successful.

\section{Conclusion}

In conclusion, the anatomical and functional outcomes of vitrectomy in RRD patients associated with grade C PVR were evaluated in this study. Favorable outcomes were obtained. After a single surgery, anatomical success was obtained in more than three-fourths of the patients had an attached retina and functional success was obtained in nearly two-thirds of the patients.

\section{Disclosures}

Ethics Committee Approval: Retrospective study.

Peer-review: Externally peer-reviewed.

Conflict of Interest: None declared.

Authorship Contributions: Concept - H.N.T., B.K.A., A.O.; Design - H.N.T., B.K.A., A.O.; Supervision - A.O.; Data collection \&/or processing - H.N.T., B.K.A., A.O.; Analysis and/or interpretation - A.O.; Literature search - B.K.A., A.O.; Writing H.N.T., A.O.; Critical review - A.O.

\section{References}

1. Iwahashi-Shima C, Sato T, Bando H, Ikeda T, Emi K. Anatomic and functional outcomes of 25-gauge vitrectomy for repair of eyes with rhegmatogenous retinal detachment complicated by proliferative vitreoretinopathy. Clin Ophthalmol 2013;7:2043-9.

2. Storey P, Alshareef R, Khuthaila M, London N, Leiby B, DeCroos C, et al; Wills PVR Study Group. Pars plana vitrectomy and scleral buckle versus pars plana vitrectomy alone for patients with rhegmatogenous retinal detachment at high risk for proliferative vitreoretinopathy. Retina 2014;34:1945-51. [CrossRef] 
3. Karakaya M, Albayrak S, Pehlivanoglu S, Ozkaya A, Gocgil NA. 5-Fluorouracyl added infusion fluid in patients with recurrent rhegmatogeneous retinal detachment. Saudi J Ophthalmol 2019;33:56-60. [CrossRef]

4. Ozkaya A, Tarakcioglu HN, Kemer B. The Outcomes of Primary Retinal Detachment Surgery with 23-gauge Vitrectomy in Patients without Severe Proliferative Vitreoretinopathy: A Single Surgeon Case Series. OR 2018;9:1-6. [CrossRef]

5. Liao L, Zhu XH. Advances in the treatment of rhegmatogenous retinal detachment. Int J Ophthalmol 2019;12:660-7.

6. Nagpal M, Chaudhary P, Wachasundar S, Eltayib A, Raihan A. Management of recurrent rhegmatogenous retinal detachment. Indian J Ophthalmol 2018;66:1763-71. [CrossRef]

7. Kreissig I. Primary retinal detachment: A review of the development of techniques for repair in the past 80 years. Taiwan J Ophthalmol 2016;6:161-9. [CrossRef]
8. Di Lauro S, Kadhim MR, Charteris DG, Pastor JC. Classifications for Proliferative Vitreoretinopathy (PVR): An Analysis of Their Use in Publications over the Last 15 Years. J Ophthalmol 2016;2016:7807596. [CrossRef]

9. Pastor JC, Rojas J, Pastor-Idoate S, Di Lauro S, Gonzalez-Buendia L, Delgado-Tirado S. Proliferative vitreoretinopathy: A new concept of disease pathogenesis and practical consequences. Prog Retin Eye Res 2016;51:125-55. [CrossRef]

10. Nemet A, Moshiri A, Yiu G, Loewenstein A, Moisseiev E. A Review of Innovations in Rhegmatogenous Retinal Detachment Surgical Techniques. J Ophthalmol 2017;2017:4310643. [CrossRef]

11. Ambiya V, Rani PK, Narayanan R, Balakrishnan D, Chhablani J, Jalali S, et al. Outcomes of Recurrent Retinal Detachment Surgery following Pars Plana Vitrectomy for Rhegmatogenous Retinal Detachment. Semin Ophthalmol 2018;33:657-63. [CrossRef] 